\title{
Social Water Technologies: Brazilian Experience of Coexistence and Development in the Semi -Arid Region of Paraiba
}

\author{
Hermes Alves de Almeida, Maria do Socorro Barbosa de Moura, Maysa Porto Farias
}

State University of Paraíba

Campina Grande, Paraíba, Brazil

\begin{abstract}
Social water technologies are alternatives that allow to associate local productive, social and economic functions. The aim of this study was to study the potential of rainwater harvesting in the Cariri micro region of Paraíba, Brazil, and the use of these types of technologies as an alternative to coexistence in this semiarid region. The geographic cut of this micro region was constituted by the localities of Barra de Santana, Cabaceiras and Riacho de Santo Antônio. The rainfall data were provided by the Paraíba Water Management Executive Agency and analyzed using statistical criteria. The other data collections were done through crazy visits, application of questionnaires, interview and documentary, being analyzed through statistical criteria. The main results indicated that the pluvial regime is irregular and asymmetric, and therefore, the use of the median is recommended. The size of the cistern volume depends on the rainfall and catchment's area and therefore should not be fixed. Farmers say that social water technologies make it possible to increase the availability of water, with the same amount of rainfall, and are therefore viable alternatives for coexistence and rural development, since it makes possible the existence of productive activity and, consequently, income on the property.
\end{abstract}

Keywords: semi-arid, rainfall, social water technology, rainwater catchment.

\section{INTRODUCTION}

The water is an indispensable element of life and therefore one of the greatest social problems in the world, since the availability of drinking water does not increase in the same proportion as population growth.

Many researchers in the area of water resources initially think that the water crisis in the 21st century is much more about management than about real water scarcity [16]. Other experts believe that water scarcity results from environmental degradation, whose main effect affects activities related to the economy and social development [8]. The aggravation and complexity of the water crisis are due not only to a decrease in availability, but also to an increase in demand coupled with a management process [18]. This condition is even worse in the rural areas of the semi-arid region of Paraíba, where lack of potable water and food malnutrition are factors that most affect the rural population.

The rainfall is the main source of water and the element of climate with greater spatial and temporal variability, especially in semi arid climate regions, such as in the semi arid Paraíba [1]. Even in the short rainy season, which lasts for about two to four months, rainfall totals are extremely irregular in quantity and distribution when comparing one location with another [16].

This characteristic in the pluvial regime has limited the water supply, even for potable purposes, and, therefore, for the use in the activities inherent to the rural environment. This water insecurity contributes not only to making the caatinga environment more fragile, but also to prevent the expansion of family agriculture, the survival of man in the countryside, and to raise the levels of social inequalities.

If the scarcity of water in the northeastern semiarid occurs even for human and animal consumption, the water is the greatest obstacle to development [5]. Although these issues have been widely discussed for a long time, there is still no alternative to increase the supply of water that meets human consumption and small agricultural production.

Even in the driest geographic micro regions of the State of Paraíba, where the low amount is associated with the spatial and temporal irregularity of the rainfall. In addition, there is a short rainy 


\section{Dr. Hermes Alves de Almeida et al.}

season even smaller, this quantitative can be well exploited, using simple rainwater harvesting technologies for human consumptions and animal disintegration and use in family production.

The Program One Million Cisterns for Drinking Water, and P1+2, the Program One Piece of Land and Two Types of Water, are examples of "Mainstreaming Rainwater Harvesting" in the context of integrated water and land management in Semi-Arid Brazil (SAB) in both policy and practice. Therefore, it aims to ensure the rural population access to land and water, both for human consumption and animal feed and for food production [10]. The P1+2 is a training and social mobilization program to coexist with the Brazilian semi-arid, therefore, similar to the One Million Cisterns (P1MC).

The participation of the various organizations aims from the functional point of view, a work that converges for the development of rural communities. Thus, rainwater catchments technologies and the various experiences of successful technologies for accessing and managing land and water can be multiplied for different environmental situations [3].

The underground dams of Northeastern Brazil offer a unique solution to this problem and a structure designed to contain underground flow, from a natural aquifer or from an artificial one, built with an impermeable barrier. There are two types: underground or submersible dams and submerged dams.

The main function of the underground dam in northeastern Brazil is to store water during the rainy season and use it during the dry season. Essentially, they are similar to above ground dams except that their reservoirs are full of sand to prevent evaporative loss. Water is stored in the porosity of the sand and extracted when needed during dry periods [20]. Thus, underground dams are highly important for the need to increase water accumulation in alluvial aquifers of intermittent watercourses.

The underground dams usually generate new opportunities for economic return in the local community, because having water can be cultivated and generate income. There are records of the use of underground flow dams since the time of the Roman Empire in Sardinia and the ancient civilizations in North Africa [5].

The multi functionality of these reservoirs is a water alternative associated to the aggregation of local productive, social and economic functions, which make it possible to irrigate orchards and family agriculture and, therefore, are water technologies that generate employment and income [19].

The project known as living with the semi-arid region $(\mathrm{P} 1+2)$ is a proposal that consists of placing the population in front of developmental possibilities, with emphasis on access to water in the rural area. In this sense, the experiences of these social technologies in this region are explained by the performance and management of the non-governmental organization of the Brazilian Semiarid Articulation (ASA).

In this context, the main objective of this work was to analyze the potential of rainwater catchment and the use of social water technologies as alternatives for coexistence and rural development in the Cariri region of Paraíba.

\subsection{Water and Development in the Northeastern Semi-Arid Region}

The water in the Northeastern semi-arid region of Brazil is a scarce resource and therefore its use and quality must be well managed. The water scarcity is undoubtedly the main factor for development in the northeastern semi-arid region, because if water is lacking even for human and animal consumption there is no family production (for subsistence and to feed the herd), the little that is planted is lost. If there is no way to produce it, the alternative is to dispose of its own patrimony, which is the raising of cattle and goats, whose main income is milk production [11].

The water is, of course, a fundamental resource for human life, but also social. Its importance exceeds the dimensions of human consumption and domestic use. The abundance or scarcity of water, for example, can be a determining factor of the consumption habits of a given community. The vast majority of the Earth's water resources are salt water, with only $2.5 \%$ being fresh water. Approximately $70 \%$ of the fresh water available on the planet is frozen in the icecaps of Antarctica and Greenland leaving the remaining $30 \%$ (equal to only $0.7 \%$ of total water resources worldwide) available for consumption [12].

Demand for water (of which agriculture already accounts for $70 \%$ of global use) would increase to unsustainable levels. Unprecedented ecosystem simplification, loss of ecosystem services and species 
extinction [14] would also occur as a result of the various pressures associated with unsustainable agricultural practices

The minimum amount of water sufficient to supply the residential demand is a controversial and complex issue, because it involves social, cultural, regional and economic aspects, including related to the sustainability of the supply systems. There is no minimum per capita daily value of 50 liters per person, as sufficient to meet the basic needs of ingestion, hygiene, sanitation and food preparation [9].

The universalization of water supply must be based on the rational use of this resource, since having a right does not mean access to unrestricted and unsustainable quantities. Thus, it should be based on the characterization of water use in the various points of the household, as well as on the pattern of consumption in different regions, which is closely related to environmental, social, economic and cultural factors [9].

Socio-economic development processes are closely related to the water resource because of the diverse range of interactions between water and human activities. Water serves as a positive input for many activities: it serves essential biological functions, as a basic element of social and economic infrastructure, and as a natural amenity contributing to psychological welfare.

The provision of good quality fresh water is essential for the quality of life of human populations, for economic development and for the sustainability of cycles on the planet. The water is not the only indispensable and important element for the development of a region, but of all the components that form part of that ecosystem, it is perhaps the main element to serve as a link between the different compartments [7].

As water is needed in all stages of life and in the semi-arid Northeast there is uncertainty of access and low availability may be reaching critical levels. A growing demand in the economy and population, with limited resources, has far-reaching implications for the region's future. Thus, the challenges related to this unavailability are in opposition to those of scarcity [4].

The development of the northeastern semi-arid region requires water security. In this sense, thinking about development, in the most diverse magnitudes, especially in the perspective of better living conditions for the population, implies reflecting on the social well-being and importance of storing water for potable and non-potable purposes.

\subsection{Social Water Technology: Brazilian Experience}

Several proposals and technological concepts called "appropriated" (TA) were developed in the 1960s and 1970s as alternatives to technologies in use in developed countries and transplanted to others [15]. The reasons were in disenchantment and skepticism with the development processes practiced at the time, which in [13] view would be a reaction to the post-war patterns of economic growth in both the First and Third World countries, although TA is believed to be a product and not a process.

Social technologies can, in general, be summarized as products, techniques or methodologies, developed and integrated with the community and which result in concrete solutions to social change.

The difficulties related to the scarcity of water in the Brazilian semi-arid region have motivated many discussions. Some palliative measures have been taken for years in an attempt to minimize the effects of droughts in the region, such as: buildings of medium reservoirs, dams and/or small dams.

The current debate permeates new ways of storing rainwater, not only by intercepting the surface runoff, but by capturing the catchment's area of the roof or soil, whether it is covered with cement or not, and the water stored in Cisterns, this type of technology is called social water technology.

The semi-arid Northeastern region, usually instigated by the media, is always cited as if it did not rain, as if droughts last for years and as if vegetation were always dry, a fact that culminated in the establishment of so-called "drought-fighting" policies.

In reality there is no way to combat the drought, but to live with it. Therefore, what it needs is public policies of coexistence with the semi-arid.

In regions with cold climates, for example, policies that are adaptable to these conditions are developed, as is the case in desert areas. The Northeastern semi-arid region seems to have not yet found the mechanisms that allow family production in this environment and, consequently, the coexistence itself, which is why the name "coexistence with the semi-arid" 


\section{Dr. Hermes Alves de Almeida et al.}

Given this evaluation, it is understood that social water technology is not only a product of scientific knowledge, but a set of aspects that involve from the social to the political. In addition, this technology involves knowledge related to science and technical skills.

Social media is emerging as an important technology for disaster response. Social media consists of tools that enable open online exchange of information through conversation and interaction [21]. Thus, social water technology is a way of giving society the responsibility to participate as manager of its resources, without waiting for decisions or changes established by governments.

In the semi-arid region of northeastern Brazil, it rains on average less than $600 \mathrm{~mm}$ per year and has a population of more than 23 million inhabitants. During the last decades, the Government of Brazil has worked with civil society to implement a large number of projects to improve livelihoods by increasing the supply of water. The 1 million cisterns projects and the programmer 1 piece of land and 2 sources of water, have become well reported [6].

It should be noted, however, that the main reason for the success of social water technologies in the rural semi-arid Northeastern region is rainwater harvesting, with the main reservoirs being cisterns, rock tanks and underground waste.

\section{MATERIAL AND METHODS}

The area covered by this work corresponds specifically to the localities of Barra de Santana (latitude

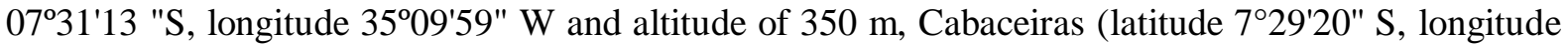
$36^{\circ} 17^{\prime} 14^{\prime \prime} \mathrm{W}$ and altitude $388 \mathrm{~m}$ ) and Riacho de Santo Antônio (latitude $7^{\circ} 41^{\prime} 15^{\prime \prime}$ S, longitude: $36^{\circ} 09^{\prime} 33^{\prime \prime} \mathrm{W}$ and altitude: $440 \mathrm{~m}$ ) In the micro region of the Eastern Cariri of the State of Paraíba, in the northeastern region of Brazil.

The criterion for choosing these localities was based on the low rainfall availability and for being still the least rainy of the micro-region of Cariri Eastern, one of the driest in the State of Paraíba. Even so, they have the potential to capture rainwater for consumption and production purposes, and thus have the potential for sustainable development.

The research procedures were descriptive and field, focusing on the description of the environmental and socioeconomic profile of the population and on the search for relations and/or contributions of water supply in local rural development. For this, semi-structured questionnaires were applied to the users of the one million cisterns and one land and two water programs.

The quantitative analyzes were made based on the statistical and qualitative criteria, sought to understand and qualify the opinions and expectations of the individuals of the population of the said localities, aiming to understand the applicability of said structures of existing social water technologies.

Rainfall data (monthly and annual) from Barra de Santana, Cabaceiras and Riacho de Santo Antônio were provided by the Executive Agency for Water Management of the State of Paraíba (AESA), and analyzed by statistical methodological climatologically data, In the article by [1].

Due to the asymmetry in the monthly and annual distribution of rains, the median was adopted as a measure of central tendency, instead of the mean. The annual accumulations were adjusted to an empirical probability distribution that resulted in the parity between the observed value and the respective probability level. Then, five scenarios were adopted with annual rainfall totals, equivalent to 25 and $75 \%$ probability levels, and those corresponding to the driest, rainiest and median years of the series. Further details of methodological procedures are contained in the [17].

Potential annual volumes of rainwater harvesting (VPC), for residential catchment's areas, and for soil-cement (boardwalk cistern) and soil in its natural cover (flood cistern), were determined using Five annual rainfall scenarios and the different sizes of the catchment's area, according to the criteria and equation proposed by [1].

Statistical analyzes calculations and confection of tables, graphs and tables were done using an Excel spreadsheet.

\section{RESULTS AND DISCUSSION}

\subsection{Social Water Technologies: Design, Type and Diagnosis}

The Programs One Earth and Two Waters $(\mathrm{P} 1+2)$ are similar to the One Million Cisterns $(\mathrm{P} 1 \mathrm{MC})$ and are intended for social formation and mobilization to coexist with the Brazilian Semi-Arid, ensuring 
the rural population access to land and water, Both for human and animal consumption as well as for food production. Therefore, this program is based on taking care of the land in a sustainable way.

The numeral "1" means the struggle for land, because there is no way to access the land without being sustainable and the "2" indicate that the program includes two types of water: drinking (human consumption) and animal and water supply for plant production.

The term "social technology" is applied broadly to the different layers of society and the adjective "social" does not mean that it applies only to the needy. Social technology is based on the principle of participation and self-management of its users. Therefore, its conception is part of a broader debate, which is that of alternative technology and therefore not neutral, but in the political context.

In the hundreds of small rural properties of the semi-arid Paraíba, the farmer is at the mercy of a short rainy season, which makes it possible to plant his subsistence crop, such as corn and beans. This condition makes it difficult to establish residence in the field, because without production there is no income and, therefore, the alternative is to migrate to medium and large cities.

How it is impossible to take all family farmers to the environments of the large reservoirs, far from their habitat, instead of looking for a technological alternative to capture rainwater in their place of origin. The underground dam and cisterns, for example, are low-cost rainwater catchment social technologies that are easy to build and operator.

The two underground dams in the municipality of Barra de Santana, PB, are very similar in construction, although there is a difference in the size of the catchment's area and the volume of stored water. The interception of water from both was done using plastic tarpaulin, masonry bleed, plus a well measuring 6 meters deep and a water box outside the reservoir to contain the excess when the well overflows.

Como essas barragens foram construídas nos últimos quatro anos, que coincidem com anos sequencialmente secos, não há dados consistentes de aumento de renda familiar e, consequentemente, de desenvolvimento social oriundo de plantios de cultivos de subsistência ou alimentaras na área de captação de água da chuva. Mesmo com esses anos em que a quantidade de chuva foi insuficiente para suprir as referidas barragens, mas há algumas expectativas positivas dessas tecnologias hídricas sociais.

In the underground dam (Figure 1), the farmer planted some rackets of the sweet palm, considering that this species is more resistant to drought when compared to the fruit or vegetable species. The planting of the forage palm, which is resistant to Cochinilla do Carmim (Dactyloius opuntiae), is for bovine feeding, due to the decimation of the traditional forage palm.

In the same dam, in the background above (Figure 1), one observes the planting of some fruit trees, but according to the farmer, they already existed before the construction of the reservoir. There had been a small plantation of corn and beans, but it was not successful because of the droughts.

When the farmer was asked about the possible benefits of this social water technology, he explained: "any benefit offered is always very welcome and the underground dams are very good because they do not evaporate water as easy as the barriers".

Farmers are expecting dams to increase family incomes through the sale of farm products. As well, there is hope of planting the forage palm to feed the herd. In addition, they hope that water can also be used for some domestic tasks, minimizing the difficulties inherent in a semi-arid environment such as this.

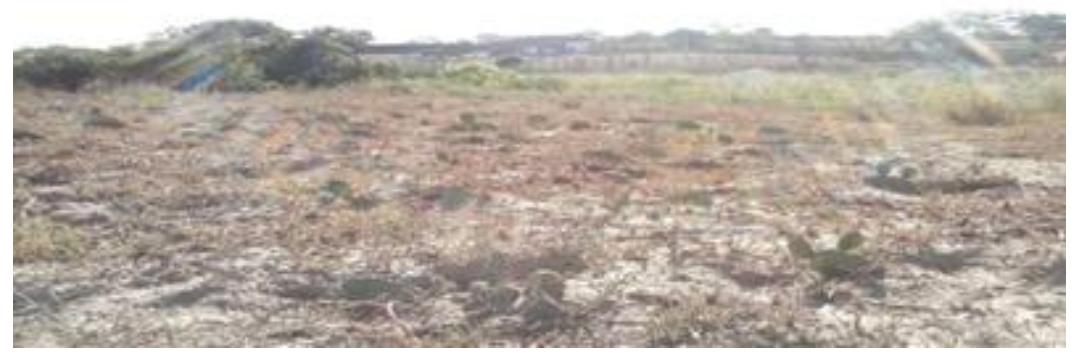

Figure1. View of Underground Dam 1(with Sweet Palm Planting and some Fruit Trees in Background) Barriguda I Site, Barra De Santana, Paraíba, Brazil 


\section{Dr. Hermes Alves de Almeida et al.}

The social water technologies of $\mathrm{P} 1+2$ are the simple, low-cost and farmer-owned technologies. The most used and/or currently used to store rainwater, collected on roofs and / or in any area, is a concrete pavement (boardwalk) and/or on the surface of the ground, with its natural cover (flooding), the tank model continues to be that of plates. It should be noted, however, that only the location of the cisterns for these catchment's areas must be constructed, naturally, in the direction of the declivity of the water flow.

Figure 2 shows the first boardwalk, with a catchment's area of $200 \mathrm{~m}^{2}$, built in cement soil, in the rural area of Barra de Santana, Paraíba, Brazil.

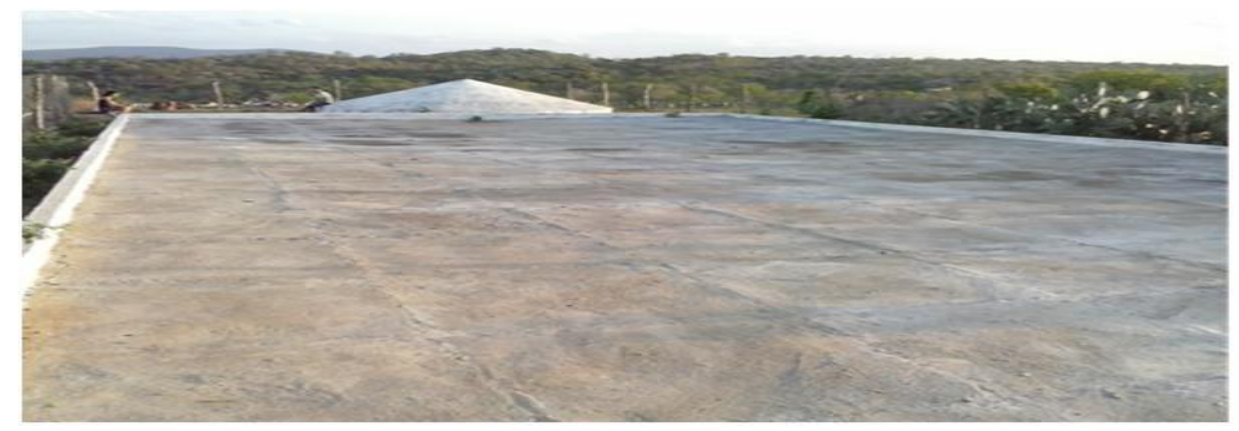

Figure2. First Boardwalk, Built in Cement Soil, to Capture Rainwater in Barra De Santana, Paraíba, Brazil

Although there is no requirement for a fixed volume of the cistern, the government program adopts the volume of 16 thousand liters for the cisterns of plates, when the capture of the rainwater is for domestic use, and of 52 thousand liters and a catchment's area of $200 \mathrm{~m}^{2}$, when picked up on boardwalks and/or on naked ground, known as boardwalks and floodplain cisterns, respectively.

The boardwalk (Figure 2) allows not only rainwater harvesting, but also for other uses, such as grain drying: beans and corn, cassava scrape, among other products during the dry season. The plate cistern with a volume of $52 \mathrm{~m}^{3}$, i.e. greater than that of the P1MC that is $16 \mathrm{~m}^{3}$, is primarily intended for the use of water in the activities of small family production and animal consumption.

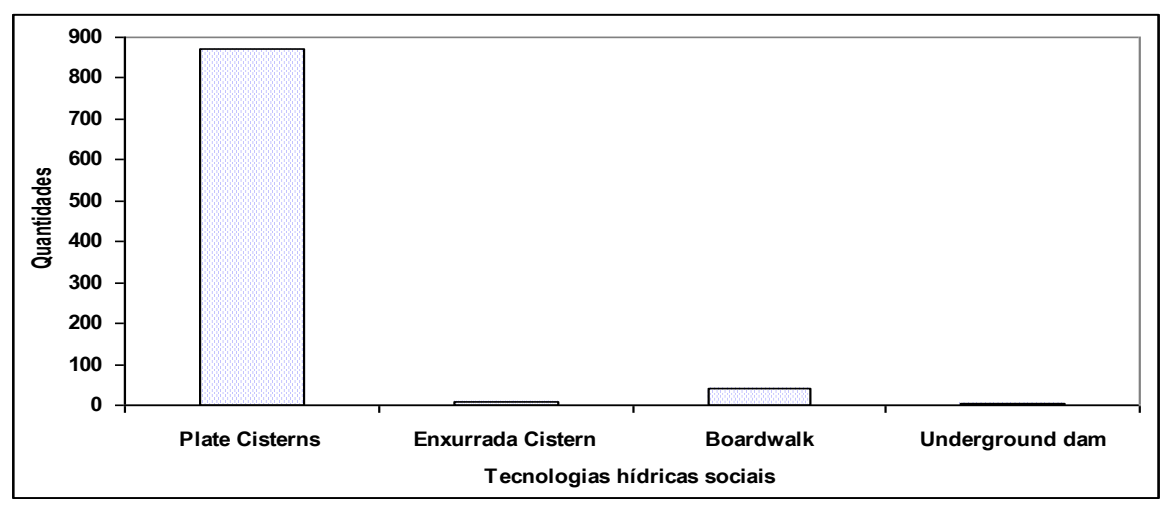

Figure3. Types of social water technologies diagnosed in the rural area of Barra de Santana, Paraíba, Brazil

The cistern and other social water technology are for collective use. Thus, Private initiatives could be fostered by compensating people for the investments they had made in producing a collective good. It is also highlighted that, due to the purpose and the acceptance of the plate cistern model, this social technology has become a public policy, since it mitigates the effect of drought in the northeastern semi-arid region. It is a simple technology, developed with the participation of the community and, therefore, the social aspect confirms what [15] describe that the cistern is a collective resource.

Figure 3 summarizes the quantitative data of the social water technologies, by type, existing in the municipality of Barra de Santana, Paraiba, Brazil.

It can be observed (Figure 4) that the largest quantity of partner technologies is of plate cisterns. This type of reservoir has already been used even before the launch of the P1MC. The cistern, in general, is a technology used to store rainwater used by the Portuguese since the 15th century and/or by the colonial and imperial governments of Brazil. However, the volume of cisterns, which includes the local rainfall regime and the amount of water needed by the family, has never been adequately sized to meet the families' needs, whether in urban or rural areas, which [1]. 
The largest number of social water technologies, built by the One Million Cisterns and One Land and Two Water P1+2 Programs, in the municipality of Barra de Santana, Brazil, focuses on the Barriguda Site. In this locality there are two of the three underground dams and in the district of Mororó, there is a greater number of cisterns of plates (with catchment's areas- residential roof, boardwalk and runoff).

It should be noted, however, that most of the plate cisterns (Figure 3) the maximum storage volume is 16 thousand liters, a value recommended by the P1MC. Its main purpose is to supply water for human consumption. The preference for this model of cistern is due to the low costs, ease of construction and durability.

There is no doubt that capturing rainwater and storing in cistern is a simple technology and therefore an important alternative to increase water supply with the same local rainfall regime as described [1]. Therefore, this technology is secular and of use in several arid and semi-arid regions of the world, especially in the rural area, because rainwater harvesting is the main source of water supply.

Rainwater harvesting in the rural area has been shown to be one of the most efficient and costeffective alternatives, besides several environmental and social advantages: there is no water loss through evaporation; Provides water during the dry season; is located near the residence and, therefore, it avoids the displacement for the search of the water.

In view of the importance of rainfall capture, especially in the northeastern semi-arid region, where the crystalline subsoil does not favor aquifer formation and, therefore, the alternative is to take advantage of rainwater. Therefore, it is necessary to establish the main characteristics of the local pluvial regime and, consequently, its potentiality as will be presented below

\subsection{Main Characteristics of the Pluvial Regime of the Micro Region of Paraíba (PB), Brazil}

Planning is an action that must be present in the decisions of the human being. In this way and before opting for rainwater harvesting technology, it is necessary to establish the local rainfall regime and then quantify the volume of water needed to meet consumption and family production.

By counting the relative frequencies, there is not much difference when comparing Cabaceiras with Riacho de Santo Antonio. Total annual rainfall above $400 \mathrm{~mm}$ occurred in about $60.0 \%$ of the years in Barra de São Miguel and 40.0\% in Cabaceiras and Riacho de Santo Antonio. It is noted that Santo Antonio Creek has the largest rainfall range, that is, it has higher and lower rainfall events of less than $300 \mathrm{~mm}$ and greater than $400 \mathrm{~mm}$ per year.

Given this spatial variability, establishing the annual local rainfall regime is a sine qua non condition for estimating rainwater harvesting potential (PCAC). The rainfall potential, in liters per $\mathrm{m} 2$, for three annual rainfall scenarios: medium, at 75\% probability and in the rainier year is shown in Figure 4.

Only for the annual rainfall median scenario, the expected quantity is around 400 liters of water for each $\mathrm{m} 2$ of catchment area. Already, at a 75\% probability level, when it is expected that in a sequence of four years, a year will rain around $480 \mathrm{~mm}$ in Riacho de Santo Antônio and $640 \mathrm{~mm}$ in Barra de Santana. Already, in the rainiest year, in any one of the localities, it rains, on average, twice the median expected.

Comparing the mean values of annual precipitation with the respective medians, it is said that they differ from one another, that is, that there is an asymmetry. Thus, the annual rainfall distribution model is asymmetric and therefore, it is recommended to use the median instead of the mean, which agrees with the indications made elsewhere by $[2 ; 1 ; 17)$ to other locations

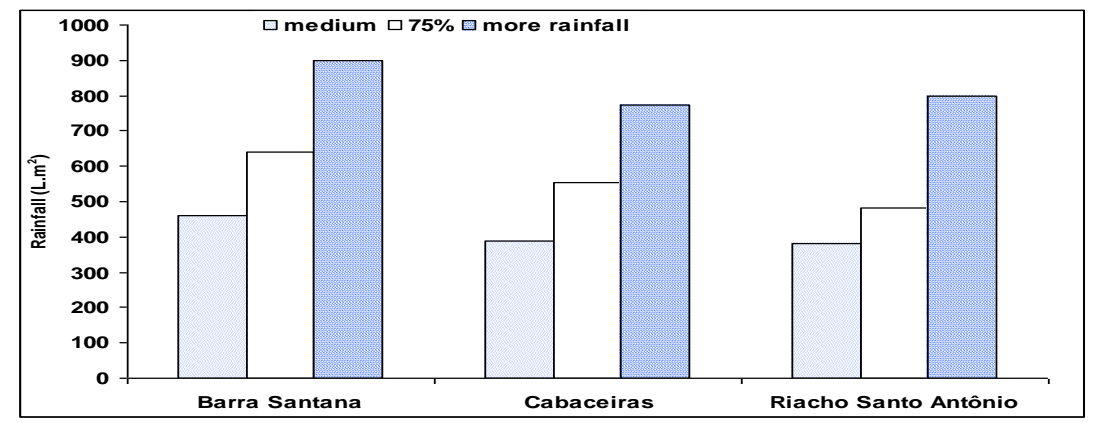

Figure4. Annual rainfall potential for three levels of probability 
Potential volumes of rainwater harvesting (VPCAC) for three sizes of catchment's areas (residential roof), are shown in Figure 5.

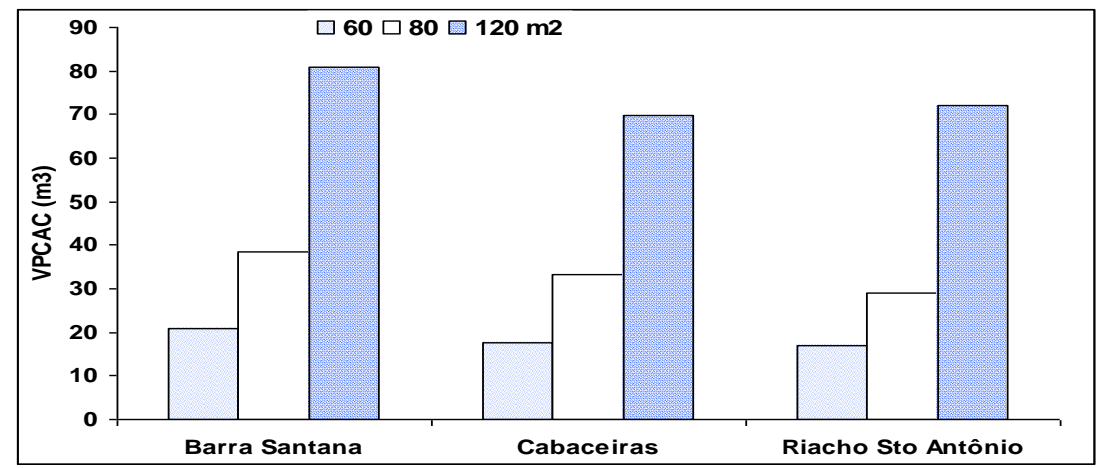

Figure5. Potential rainwater harvesting volume for three catchment's areas (residential roof)

In the literature it mentions differentiated values of water use for domestic purposes, which vary from14 and $200 \mathrm{~L}$. hab ${ }^{-1} \cdot \mathrm{d}^{-1}$. Even so, rural cisterns (boards) built and / or distributed by the Federal Government, other Institutions and Non-Governmental Organizations (ONGs) have the capacity to store $16 \mathrm{~m}^{3}$ of water (16 thousand liters).

As cisterns have a fixed volume, the potential volume of rainfall for each site, the size of the residential catchment's area and the number of water users was not used for their design. Obviously, there is no way to fix a single value, because these conditions have to be included in the sizing of the cistern.

However, it is worth noting that it is a mistake to standardize a single volume for the cisterns, without knowing how much water is needed to meet the needs of the family, the local rainfall regime, the size of the catchment's area and the volume of water needed. Without this knowledge, the volume of the cistern can be sub or over-dimensioned.

The sidewalk-type cistern is a social water technology developed to serve semi-arid families with the main purpose of using water for family production. In this model, the catchment's area is a boardwalk and not the roof of the house and the water tank (cistern) is connected to it. In terms of reference, the catchment's area is $200 \mathrm{~m}^{2}$ and the cistern volume is 52 thousand liters.

Potential volumes of rainwater harvesting (VPC), for sidewalks with areas of 200,300 and $400 \mathrm{~m}^{2}$ and in the average annual rainfall scenario, are presented in Figure 6. It can be observed that, even for a smaller area $\left(200 \mathrm{~m}^{2}\right.$ boardwalk), the volume captured exceeds the 52 thousand liters recommended in the government program. This demonstrates, therefore, that one should not "standardize" the area of the sidewalk and/or volume of the cistern. Standardization that under or overestimate the catchment's potential that is a function of the local rainfall regime.

For the same reasons as non-standardization of single volume for domestic cisterns, those of the sidewalk cisterns apply. The volumes presented in Figure 6 show clearly and objectively that the tank volume should not be set at $52 \mathrm{~m}^{3}$, but the quantity needed to meet the water requirement, as established by the $\mathrm{P} 1+2$ program. It can be observed in the said Figure that a board of $400 \mathrm{~m}^{2}$, for example, in the two driest localities, still captures more than 230 thousand liters of water per year, that is, more than four times the volume of the tank of 52 thousand Liters.

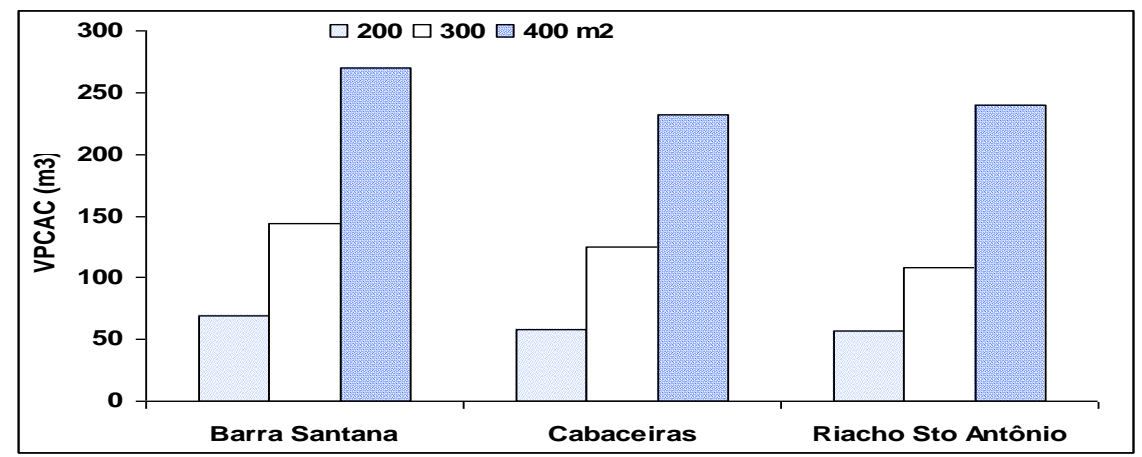

Figure6. Potential volume of water abstraction from rainwater, for three catchment's areas (cistern boardwalk) 
In the northeastern semi-arid region, in addition to the cisterns (plaques), boardwalks and floods, there are other social water technologies, such as Barraginha (Figure 7), built two to three meters deep, with diameters varying from 12 to 30 meters, in the shape of a shell or semicircle.

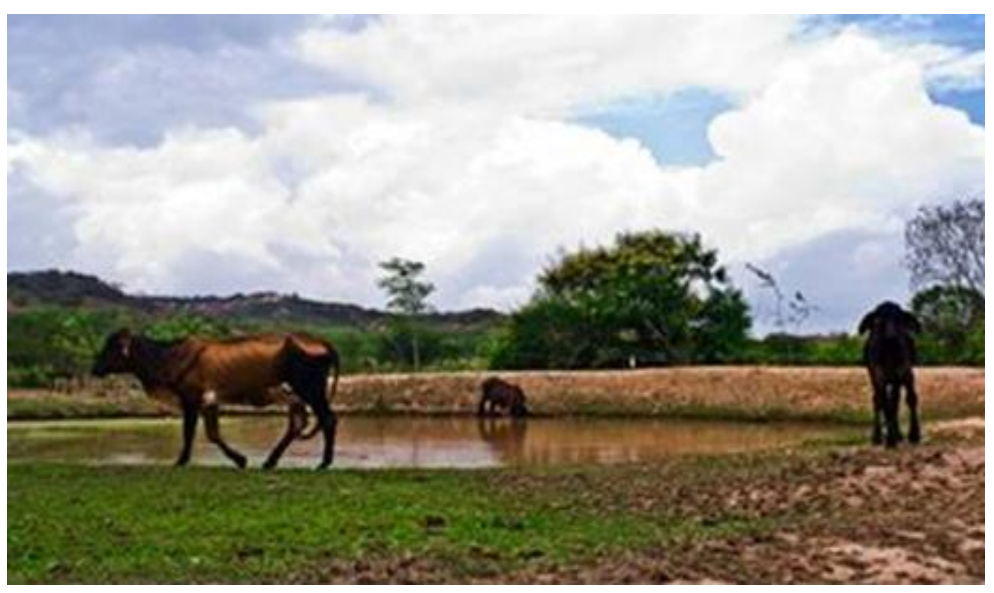

Figure7. View of social technology called Barraginha.

The barraginha stores rainwater for about two to three months, for example, which allows the soil to moisten for a longer period. This technology provides a condition for agro ecological management improves soil quality by accumulating organic matter and keeps the microclimate around the most pleasant barraginha.

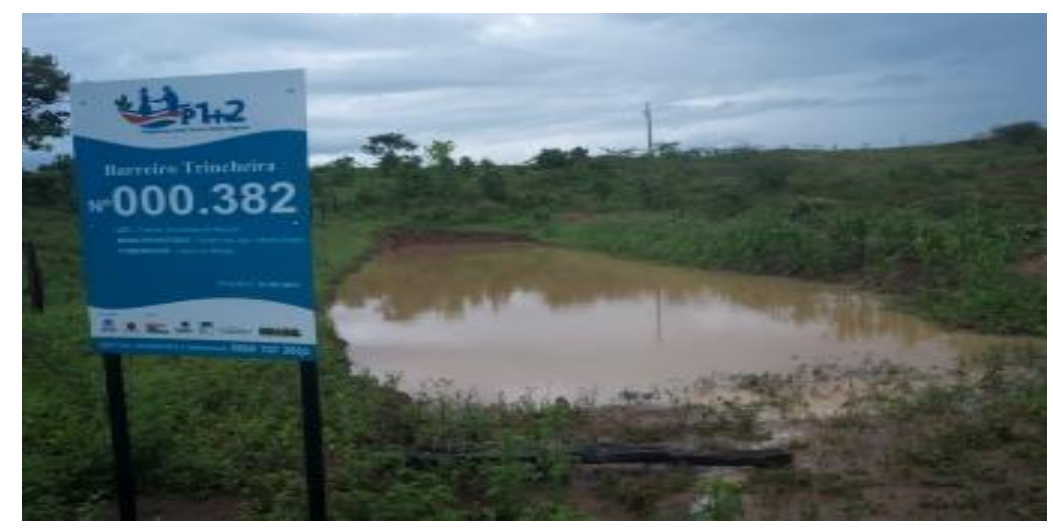

Figure8. View of a trench type barrier

The Barreiro Trincheira (Figure 8) is a long, narrow tank with the bottoms dug into the ground. Construction requires flat and close to the production area. With the capacity to store at least 500 thousand liters of water, the bar-trench has the advantage of being narrow, which reduces the losses by evaporation.

Isolated rocky outcrops that emerge abruptly above the plains are ancient geological formations and occur in several regions of the world. The rock that emerges from the surface is rounded in the form of lenses and with superficial caves where rainwater naturally accumulates, forming Tanks (Figure 9).

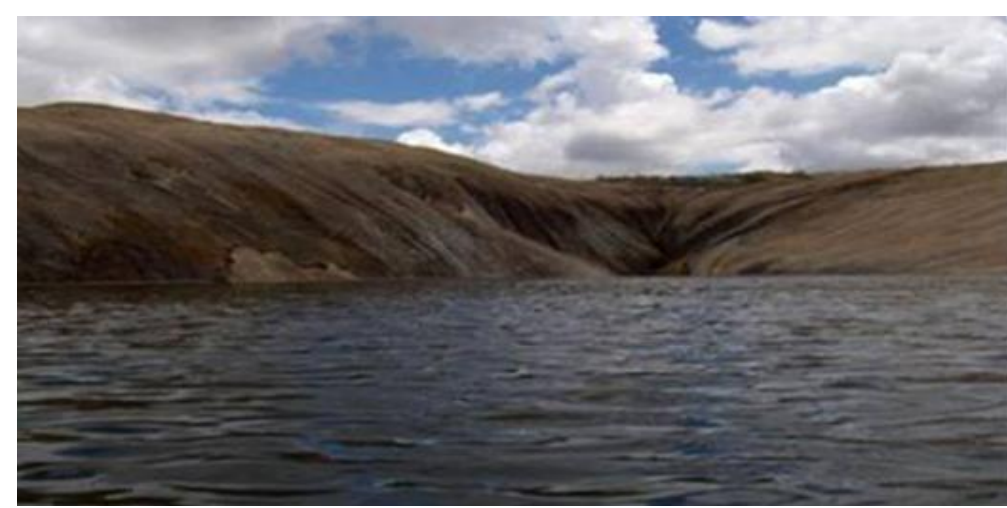

Figure9. View of a Stone Tank, Pocinhos, Paraiba, Brazil 


\section{Dr. Hermes Alves de Almeida et al.}

These natural structures, formed in the rocky outcrops, using their own cracks, baroque or natural holes, usually granite, whose surfaces capture rainwater, flow on the slabs in the direction of natural inclination, and store large volumes.

To further increase the volume of stored water walls or masonry walls are erected in the lower part or around to spread more water. The use of water has different purposes, besides human and animal consumption of irrigating orchard.

\section{Conclusions}

The rainfall distribution regime is irregular and asymmetrical, so it is recommended to use the median instead of the mean.

The volume of the cistern must be sized according to the local rainfall regime and the size of the catchment's area in order to capture a volume of water necessary for consumption and production.

Farmers argue that social water technologies for rainwater harvesting are important alternatives for living with the semi-arid region, because it allows increasing the supply of water, with the same rainfall regime, and for enabling family productive activity and, consequently, Income on the property.

\section{REFERENCES}

[1] Almeida, H. A, de and Farias, M. P. Potential for rainwater catchment's as an alternative for human consumption in drier micro-region of the state of Paraiba, Brazil. International Journal of Research in Geography (IJRG), v.1, n.2, p.32-37, 2015.

[2] Almeida, H. A. de. Climate, water and sustainable development in the semi-arid of northeastern Brazil. In: Bilibio, C.; Hensel, O.; Selbach, J. F. (Organizers). Sustainable water management in the tropics and subtropics and case studies in Brazil, Unikaseel, Alemanha, v.3, p.271-298, 2012.

[3] Brito, L. T. L.; Moura, M. S. and Gama, G. F.B. Potencialidades da água de chuva no semi-árido brasileiro. Petrolina, PE: Embrapa Semiárido, 2007, 181p.

[4] Campos, J. N. B. Água, sociedade e natureza: desenvolvimento científico e gestão das águas. In: Fundação Konrad Adenauer. Água e desenvolvimento sustentável no semiárido. Fortaleza, Série Debates, $n^{\circ}$ 24, dez. 2002.

[5] Cirilo, J. A. Public Water Resources Policy for the Semi-Arid Region. Estudos Avançados, v.22, n.63, p. 61-82, 2008.

[6] Heijnen, H. Enhancing economic resilience in North Easten Brazil by harnessing rain. Rain Foundation, Amsterdam, 43p, 2013

[7] EPA- Environmental Protection Agency. Disponível em: <http://www.epa.gov/owow/... Acesso em: 10 de maio de 2009.

[8] Gleick, P. H. The world's water. 2000-2001. Report on Freshwater Resources. Island Press, 2000. 315p, 2000.

[9] Gleick, P Basic water requirements for human activities: meeting basic needs. Water International, 21, 83-92, 1996

[10] Gnadlinger, J., Community water action in semi-arid Brazil: an outline of the factors for success, Official Dele-gate Publication of the 4 th World Water Forum Mexico City, March,16 - 22, 2006.

[11] Hauschild, M. and Döll, P. Water Use in Semi-arid Northeastern Brazil - Modeling and Scenario Analysis. Report A0003, Center for Environmental Systems Research, University of Kassel, 34109 Kassel, Germany, 80pp, 2000

[12] IPCC, 2007: Climate Change 2007: Impacts, Adaptation and Vulnerability. Contribution of Working Group II to the Fourth Assessment Report of the Intergovernmental Panel on Climate Change, M.L. Parry, O.F. Canziani, J.P. Palutikof, P.J. van der Linden and C.E. Hanson, Eds., Cambridge University Press, Cambridge, UK, 976pp, 2007

[13] Kaplinski, R. The economies of small: appropriate technology in changing world. London: Intermediate Technology Publications, 1990

[14] Loreau, M.; Naeem, S.; Inchausti, P.; Bengtsson, J.; Grime, J.P.; Hector, A.; Hooper, D.U.; Huston, M.A.; Raffaeli, D.; Schmid, B.; Tilman, D. and Wardle, D.A. 2002. Biodiversity and ecosystem functioning: current knowledge and future challenges. Science, 294: 804-808 
[15] Rodrigues, I and Barbieri, J. C. A emergência da tecnologia social: revisitando o movimento da tecnologia apropriada como estratégia de desenvolvimento sustentável. Revista de Administração Pública, v. 42, n.6, p. 1069-94, 2008.

[16] Rogers, P. P.; Llamas, M. R. and Martinez-Coretina, L. Water crisis: myth or reality? London: Fundación Marcelino Botín, Taylor \& Francis, 333p, 2006.

[17] Sampaio, E. A. M. and Almeida, H. A. de. Main geological characteristics and rainwater catchment in natural tanks in the semi-arid northeastern Brazil. International Journal of Geology, Agriculture and Environmental Sciences, v. 4, n.4. p. 20-25, 2016.

[18] Somlyod, Y. L. and Varis, O. Freshwater under pressure. International Review for Environmental Strategies, v.6, n.2, p.181-204, 2006.

[19] Saborin, E. Multifuncionalidade da agricultura e manejo dos recursos naturais: alternativas a partir do caso do semiárido brasileiro. Tempo da ciência. UNB/CIRAB-FR. p.9-27, $1^{\circ}$ semestre 2008.

[20] Telmer, K. and Best, M. Underground dams: a practical solution for the water needs of small communities in semi-arid regions. Scientific Communications. TERRÆ, 1(1):63-65, 2004 [UNESCO, 1987]

[21] Yates, D. and Paquette, S. Emergency knowledge management and social media technologies: A case study of the 2010 Haitian earthquake. International Journal of Information Management, v.31, p. 6-13, 2011.

\section{AUTHORS' BIOGRAPHY}

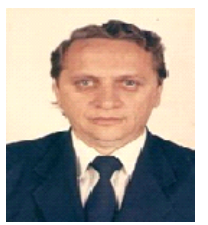

Hermes Alves de Almeida, graduated in Meteorology with $\mathrm{MA}$ and $\mathrm{PhD}$ in Agrometeorology. Associate Professor, Department of Geography at the State University of Paraíba (UEPB) and the Graduate Program in Geography and Regional Development. Researcher of the areas of general and geographical climatology and water alternative to the semi-arid. It has published over 100 scientific articles, research team leader and adjunct coordinator of the postgraduate program in regional development.

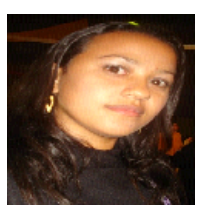

Maria do Socorro Barbosa de Moura, Graduate in Geography with master's degree in regional development. Geography teacher of the key state-level education system and medium. It operates in research area in geographical climatology and water alternative for regional development

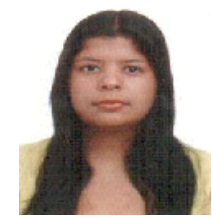

Maysa Porto Farias, Graduate in Geography with master's degree in regional development. Geography teacher of the key state-level education system and medium. It operates in research area in geographical climatology and water alternative for regional development. 